Supplement of Ocean Sci., 13, 315-335, 2017

http://www.ocean-sci.net/13/315/2017/

doi:10.5194/os-13-315-2017-supplement

(C) Author(s) 2017. CC Attribution 3.0 License.

(c) (i)

Supplement of

\title{
Large-scale forcing of the European Slope Current and associated inflows to the North Sea
}

Robert Marsh et al.

Correspondence to: Robert Marsh (rma@noc.soton.ac.uk)

The copyright of individual parts of the supplement might differ from the CC-BY 3.0 licence. 
Figure S1. Particle density maps $\left(0.5^{\circ} \times 0.5^{\circ}\right.$ resolution) for all ensembles of forward trajectories starting on 1 July, 1988-2007. The logarithmic scale for density, ranging from -4 to -1 , equates to $0.01-10 \%$ of all particle positions.

Figure S2. Particle age maps (binned at $0.5^{\circ} \times 0.5^{\circ}$ resolution) for all ensembles of forward trajectories starting on 1 July, 1988-2007 (days since 1 July).

Figure S3. Particle salinity maps (binned at $0.5^{\circ} \times 0.5^{\circ}$ resolution) for all ensembles of forward trajectories starting on 1 July, 1988-2007 (days since 1 July).

11 Figure S4. As Fig. S1, for backward trajectories.

12 Figure S5. As Fig. S2, for backward trajectories.

Figure S6. Monthly-mean transport at the three Slope Current sections and the JONSIS 14 section.

Figure S7. (a) mean absolute dynamic topography (MADT); (b) mean $\sigma_{0}$ at 500m; (c) meridional gradient of MADT, i.e., the left hand side of Eq. (7); (d) meridional gradient of $\sigma_{0}$, scaled by $-H / \rho$ (nominally $1027 \mathrm{~m} / 1027 \mathrm{~kg} \mathrm{~m}^{-3}$ ) i.e., the right hand side of Eq. (7).

Figure S8. Potential density $\left(\sigma_{0}\right)$ at 500 m, 1-5 January biennially, 1988-2006, ORCA1219 N01.

Figure S9. Potential density $\left(\sigma_{0}\right)$ at $947 \mathrm{~m}, 1-5$ January biennially, 1988-2006, ORCA1221 N01.

Figure S10. Monthly salinity at the four sections over 1980-2016, sampling NCEP Global Ocean Data Assimilation System (GODAS) analysis fields.

Figure S11: Monthly salinity anomalies at the four sections over 1980-2016, obtained by subtracting climatological seasonal cycles from the time series in Fig. S10.

Figure S12. Comparison of ORCA12-N01 and ORCA12-N06 hindcasts over 1988-2007: 5-day averages of sea level difference, Lerwick minus Torshavn (top panel); ORCA12N01 minus ORCA12-N06 differences (middle panel); scatterplot of individual sea level differences. 

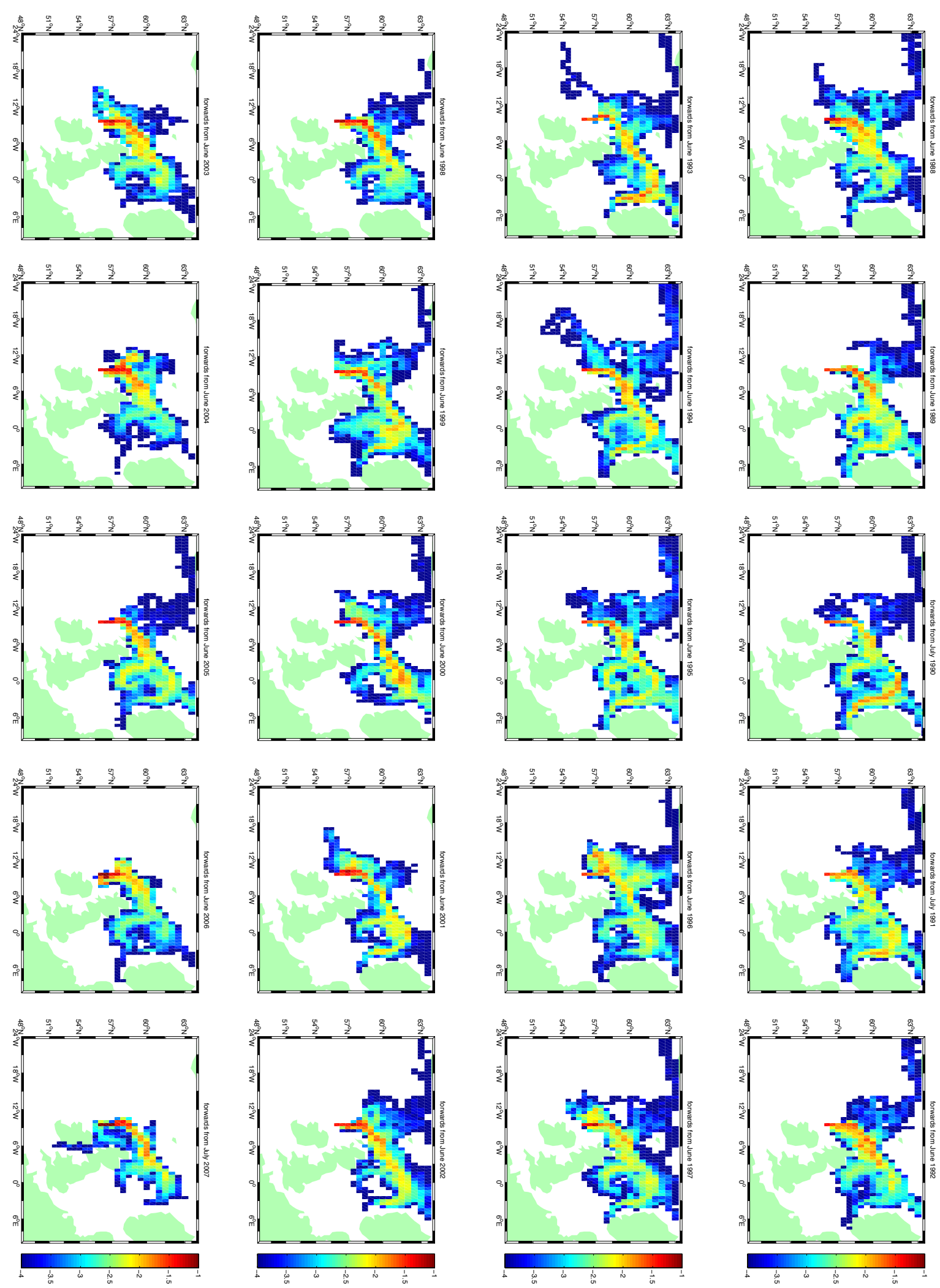

2 Figure S1. Particle density maps $\left(0.5^{\circ} \times 0.5^{\circ}\right.$ resolution) for all ensembles of forward 3 trajectories starting on 1 July, 1988-2007. The logarithmic scale for density, ranging 4 from -4 to -1 , equates to $0.01-10 \%$ of all particle positions. 

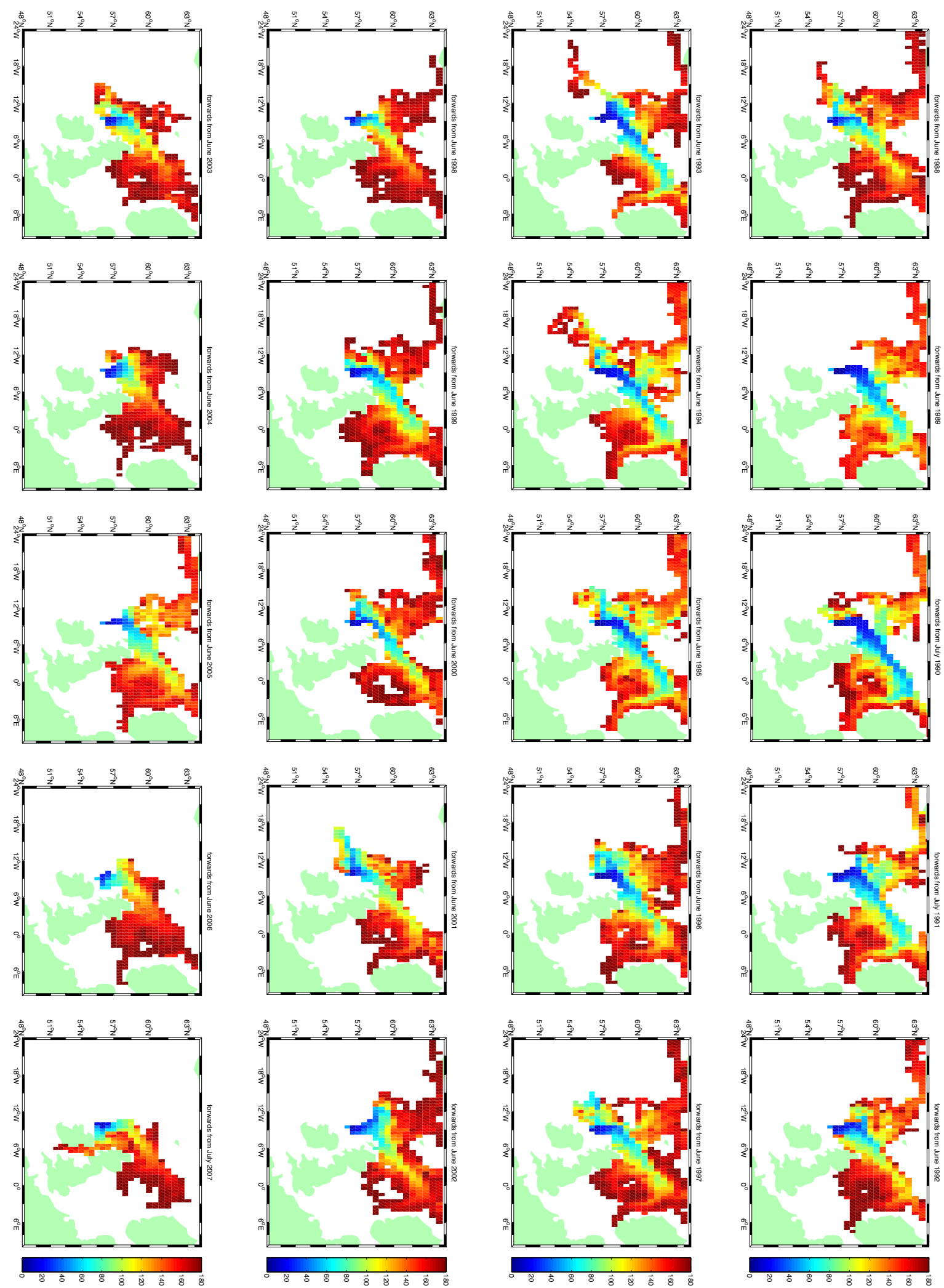

Figure S2. Particle age maps (binned at $0.5^{\circ} \times 0.5^{\circ}$ resolution) for all ensembles of forward trajectories starting on 1 July, 1988-2007 (days since 1 July). 

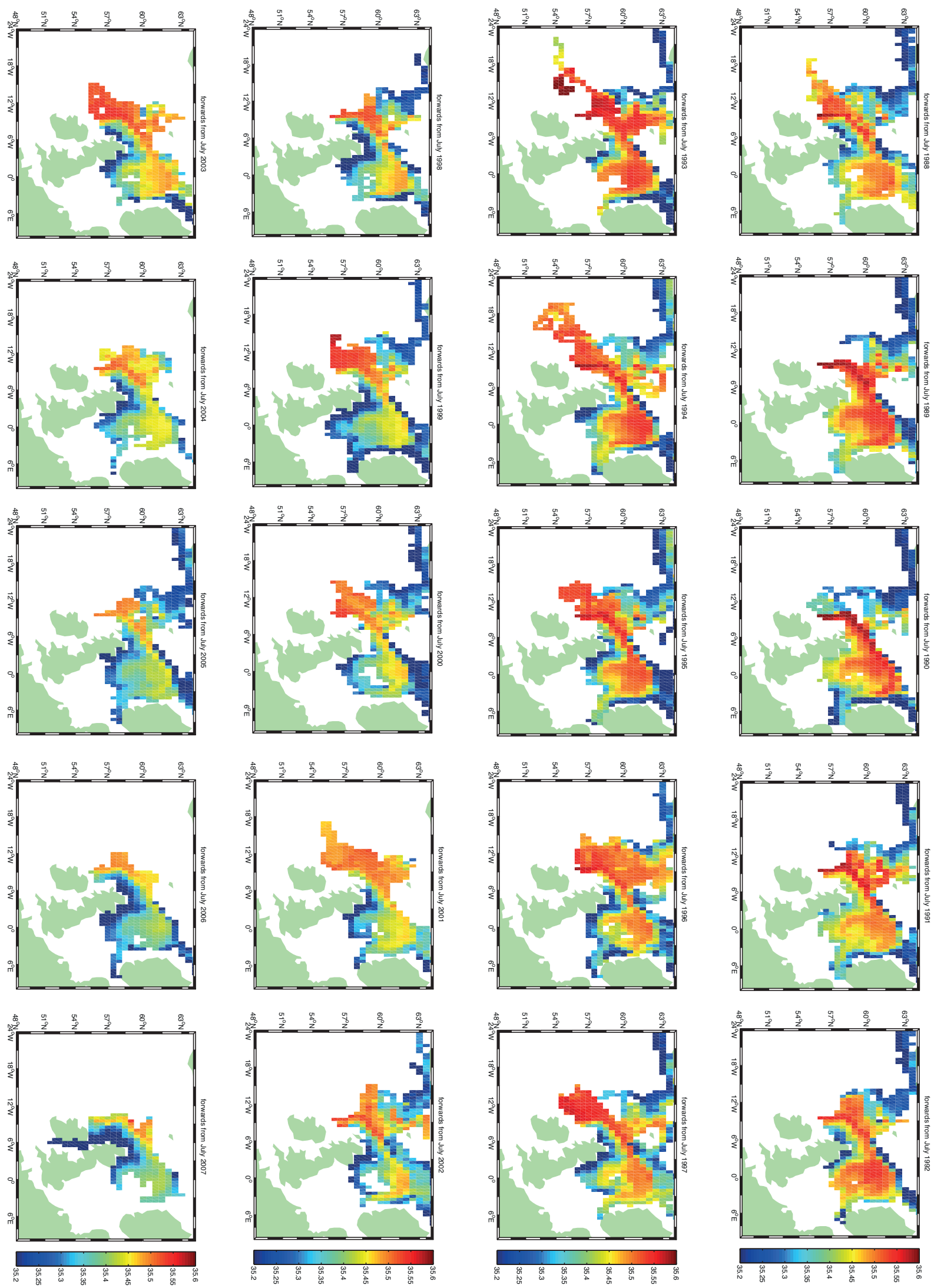

Figure S3. Particle salinity maps (binned at $0.5^{\circ} \times 0.5^{\circ}$ resolution) for all ensembles of forward trajectories starting on 1 July, 1988-2007 (days since 1 July). 

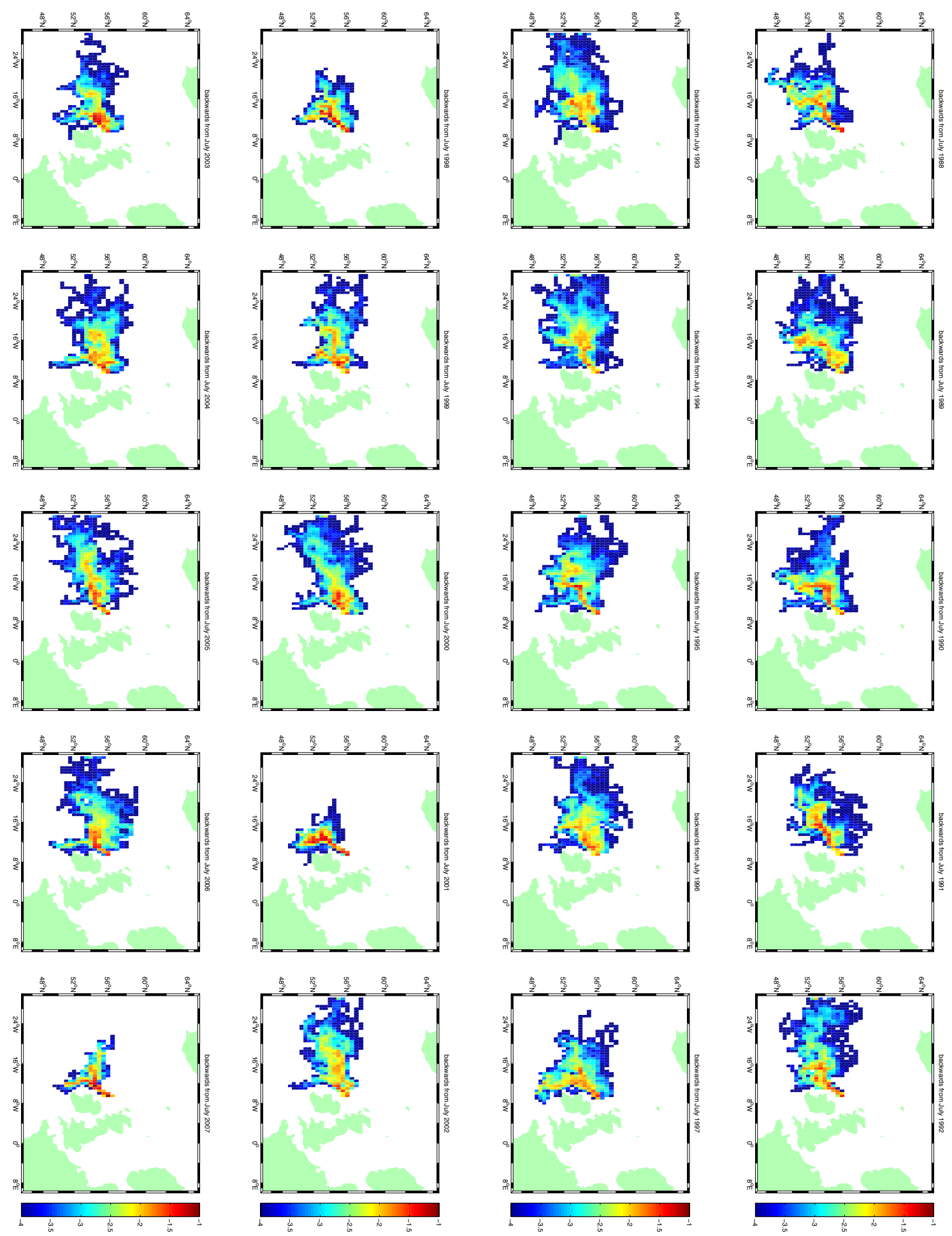

2 Figure S4. As Fig. S1, for backward trajectories. 

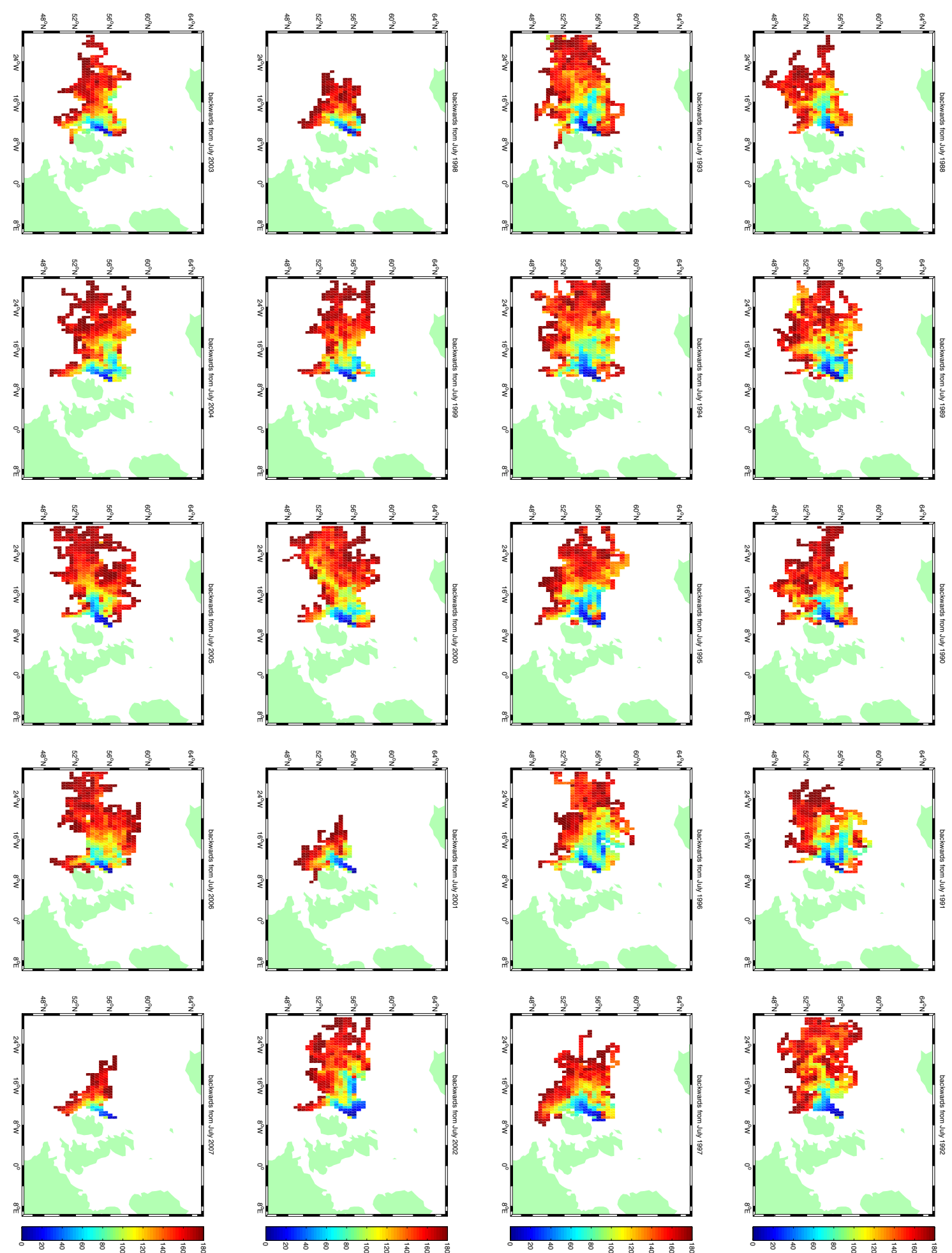

2 Figure S5. As Fig. S2, for backward trajectories. 
(a) FASTNEt section

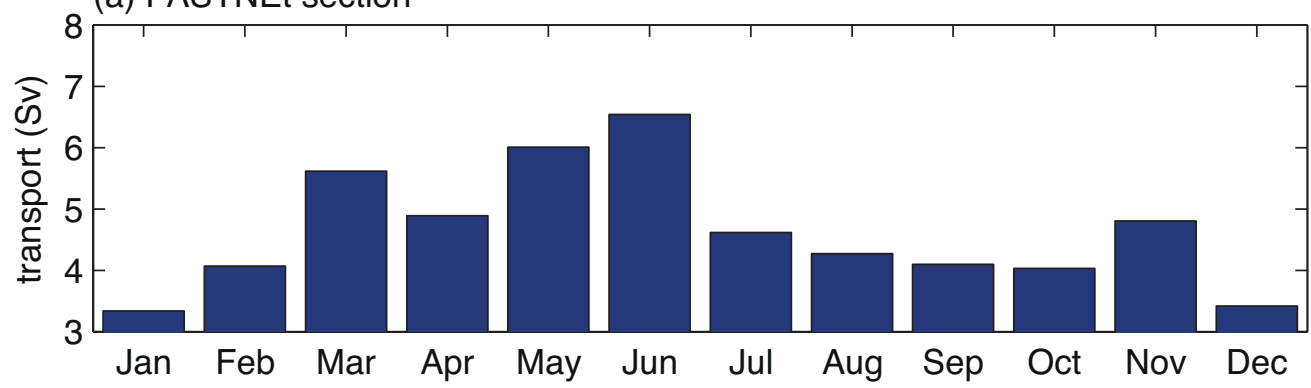

(b) EEL section
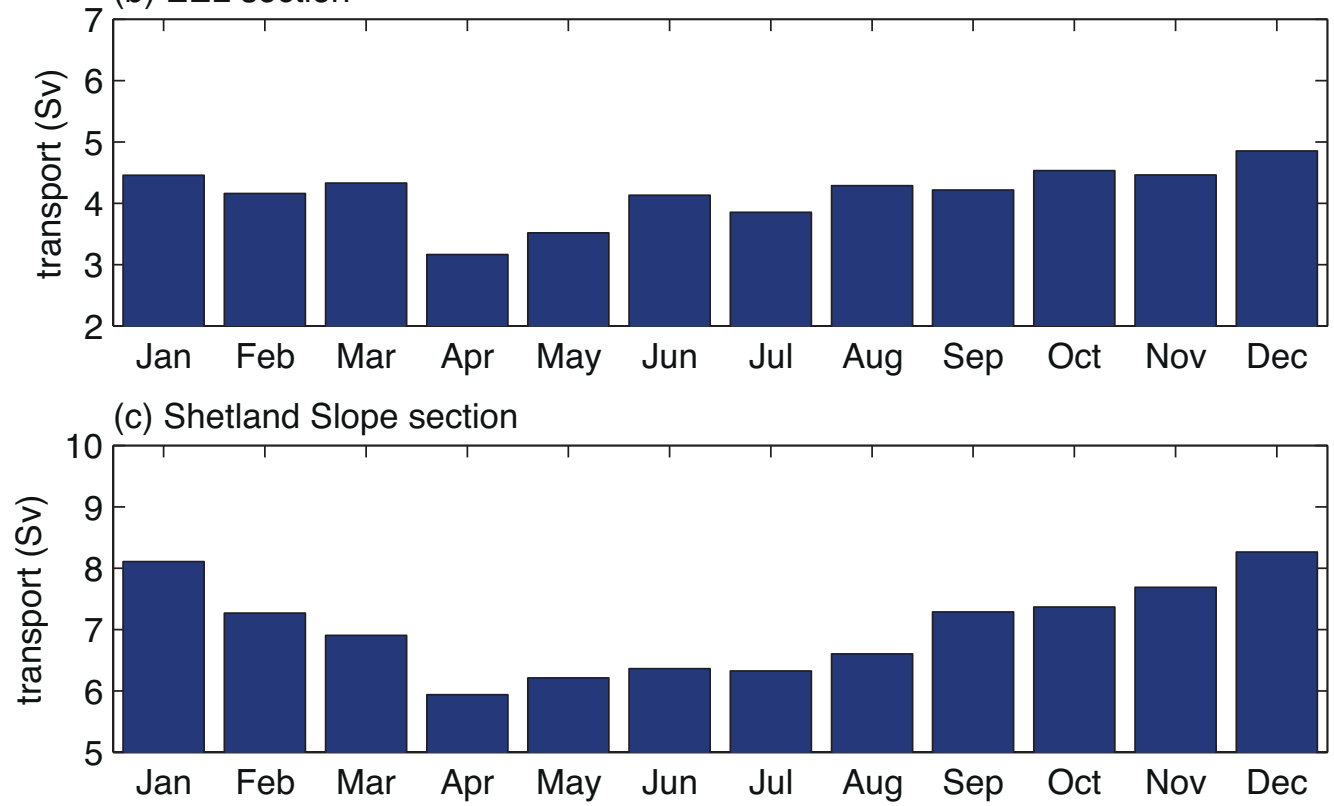

(d) JONSIS section

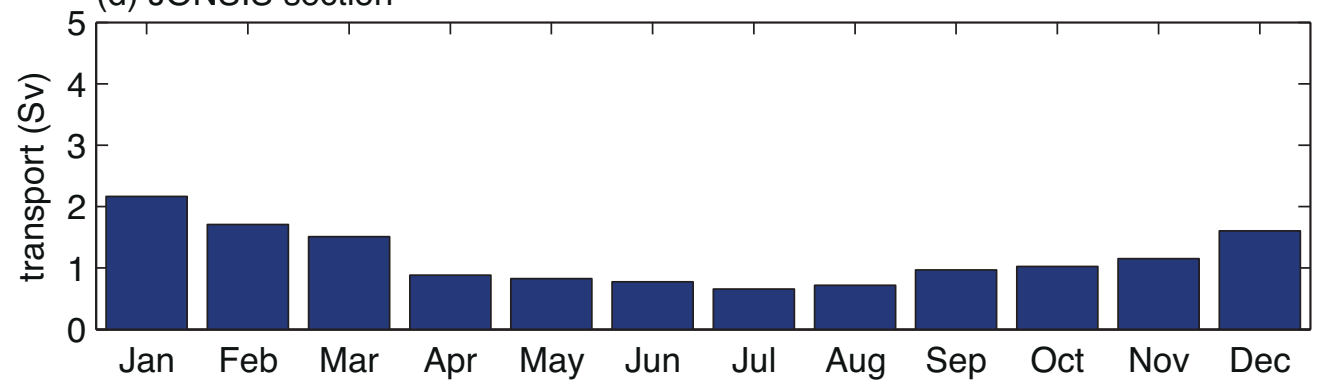

Figure S6. Monthly-mean transport at the three Slope Current sections and the JONSIS section. 

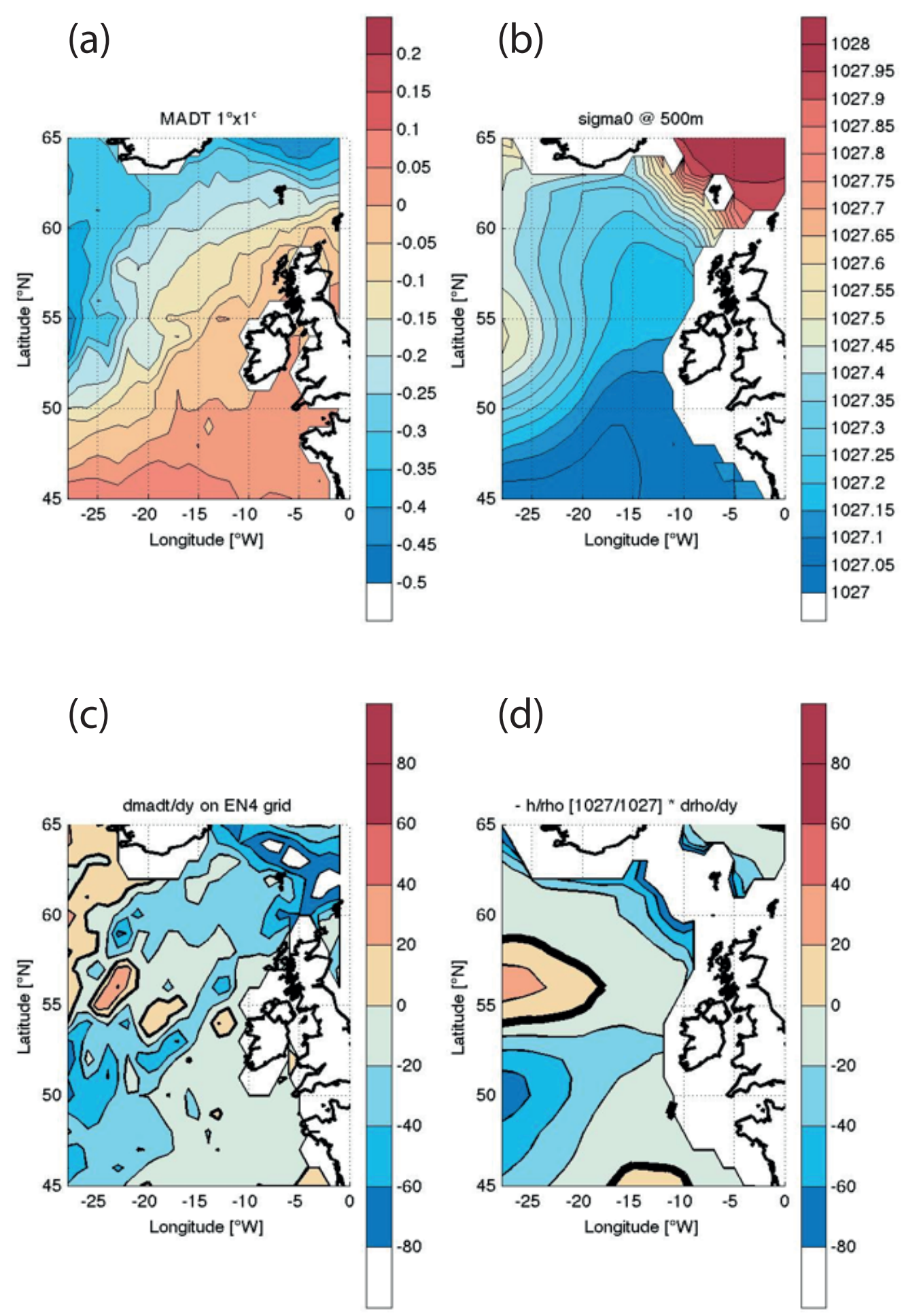

2 Figure S7. (a) mapped absolute dynamic topography (MADT); (b) mean $\sigma_{0}$ at 500m; (c) 3 meridional gradient of MADT, i.e., the left hand side of Eq. (7); (d) meridional gradient 4 of $\sigma_{0}$, scaled by $-H / \rho$ (nominally $1027 \mathrm{~m} / 1027 \mathrm{~kg} \mathrm{~m}^{-3}$ ) i.e., the right hand side of Eq. (7). 

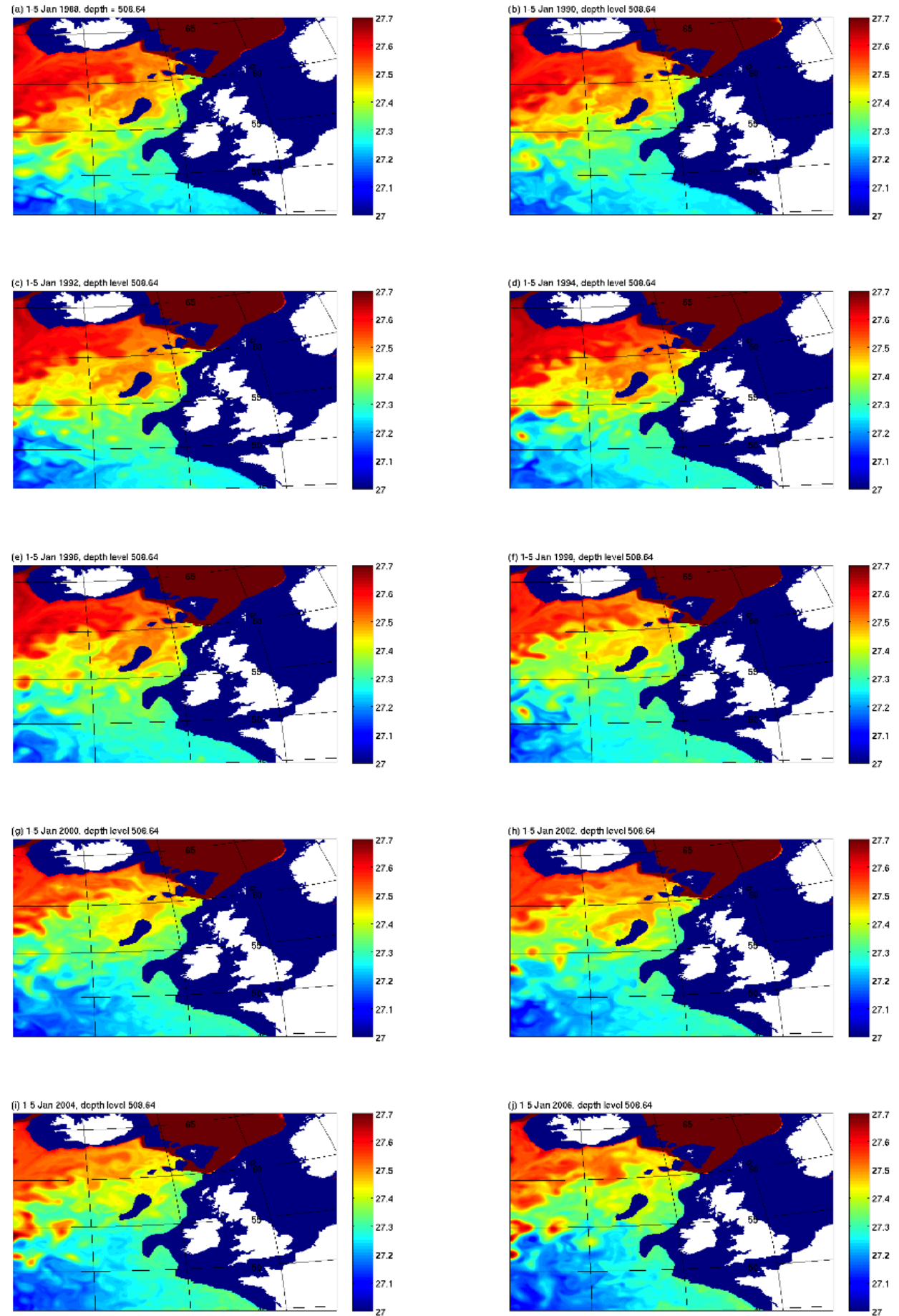

2 Figure S8. Potential density $\left(\sigma_{0}\right)$ at 500 m, 1-5 January biennially, 1988-2006, ORCA123 N01. 

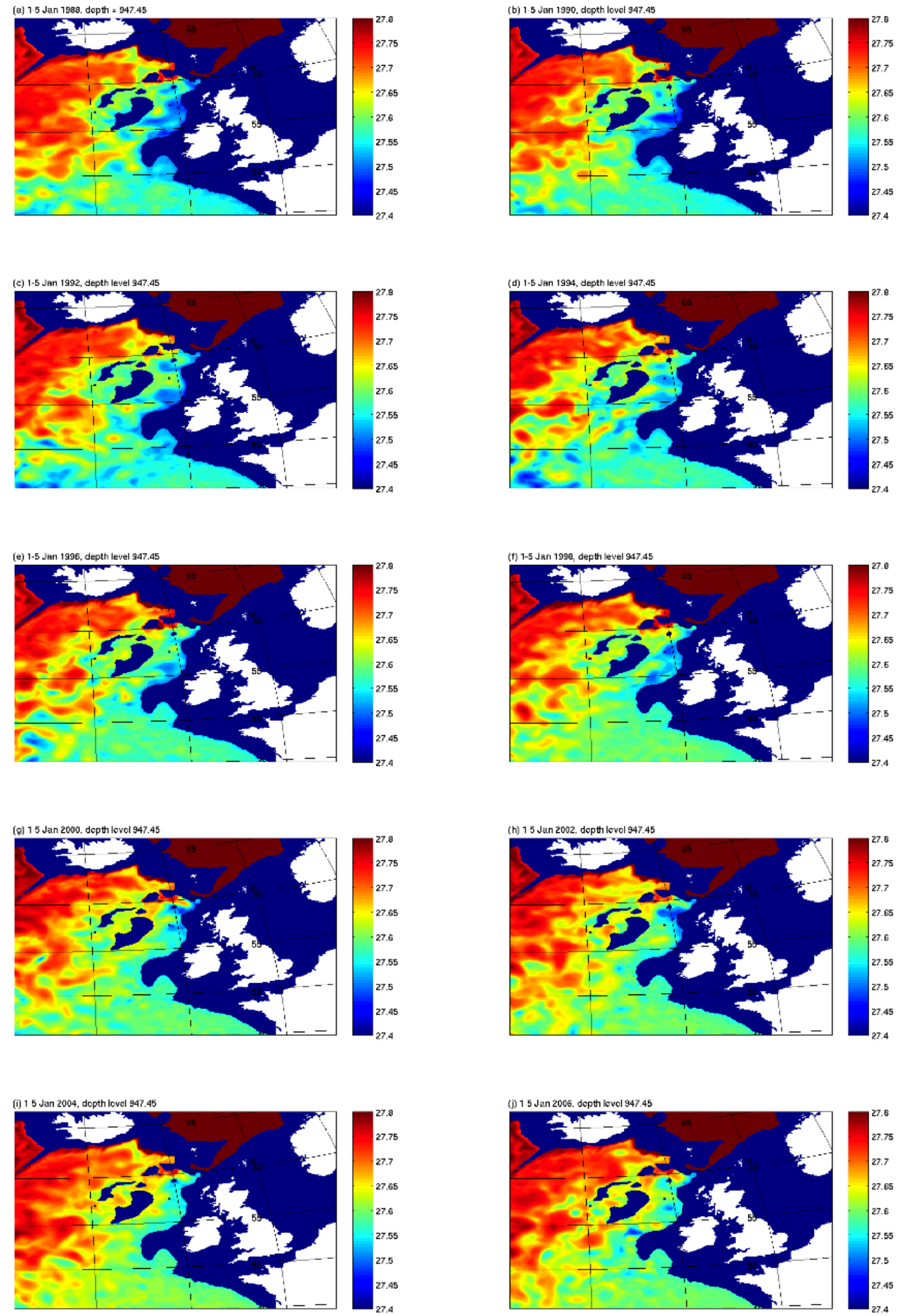

2 Figure S9. Potential density $\left(\sigma_{0}\right)$ at $947 \mathrm{~m}, 1-5$ January biennially, 1988-2006, ORCA123 N01. 
(a) FASTNEt section

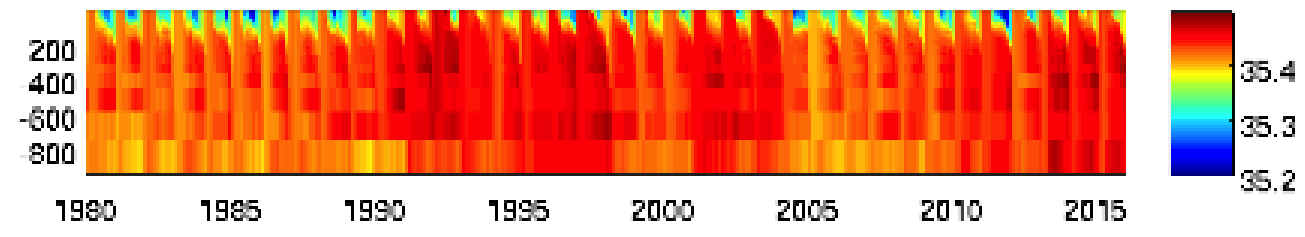

(b) EEL section

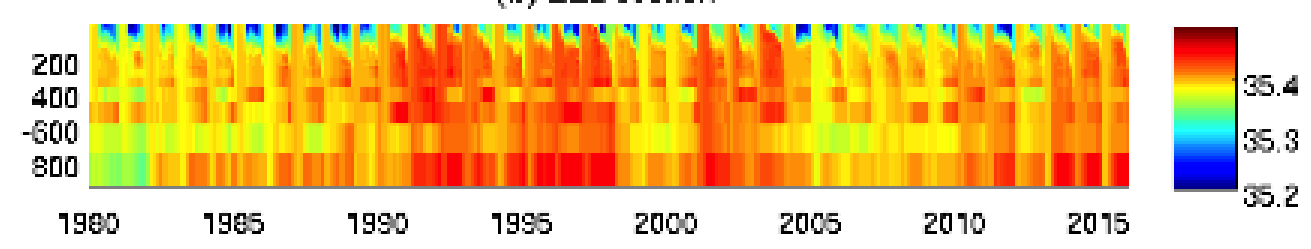

(c) Shetland Shelf section

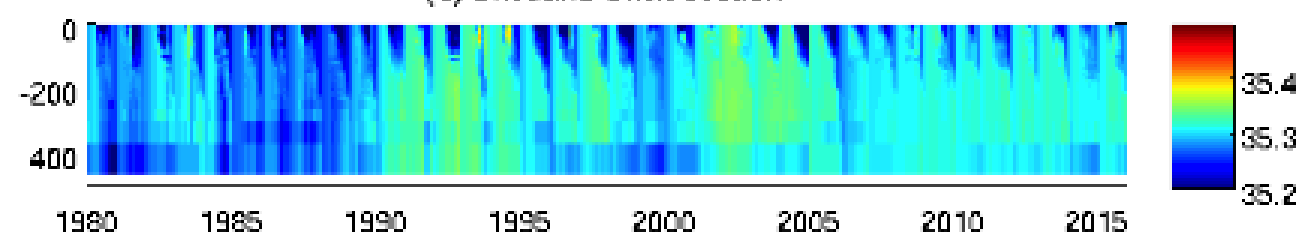

(d) JONSIS section

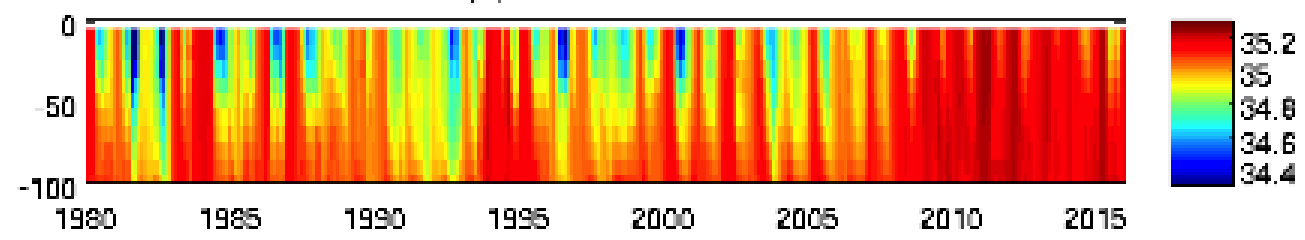

1

2 Figure S10. Monthly salinity at the four sections over 1980-2016, sampling NCEP Global

3 Ocean Data Assimilation System (GODAS) analysis fields. 
(a) FASTNEt section

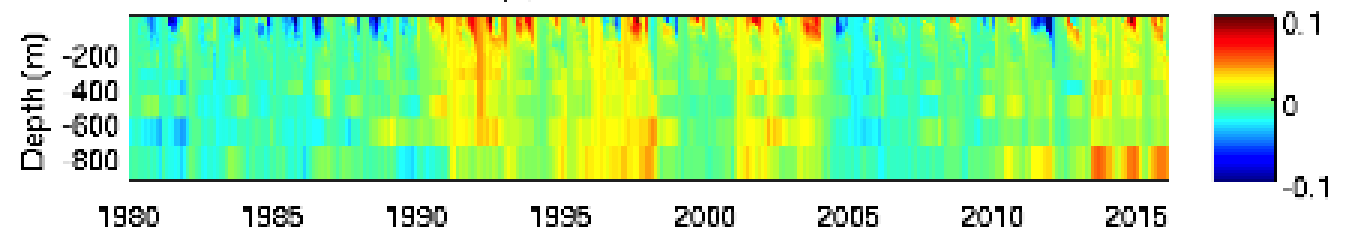

(b) EEL scction

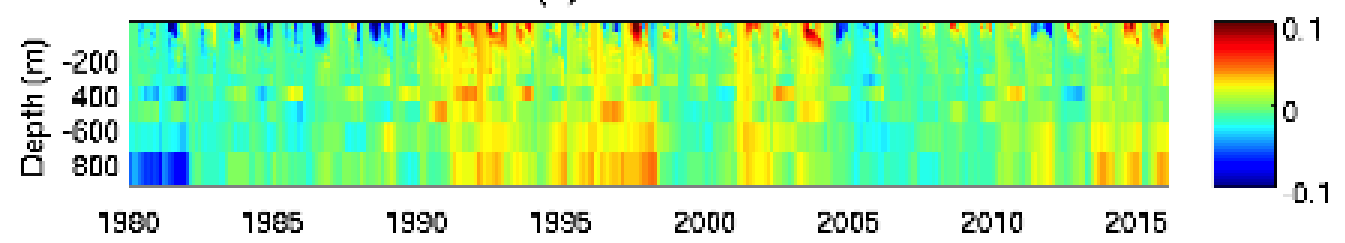

(c) Shetland Shelf scetion

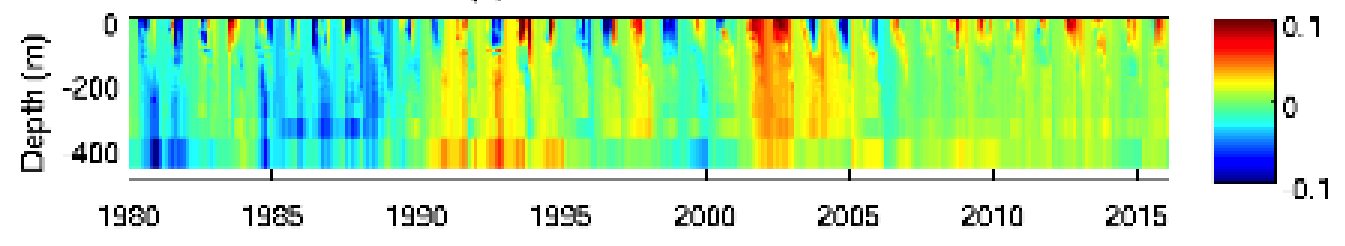

(d) JONSIS section

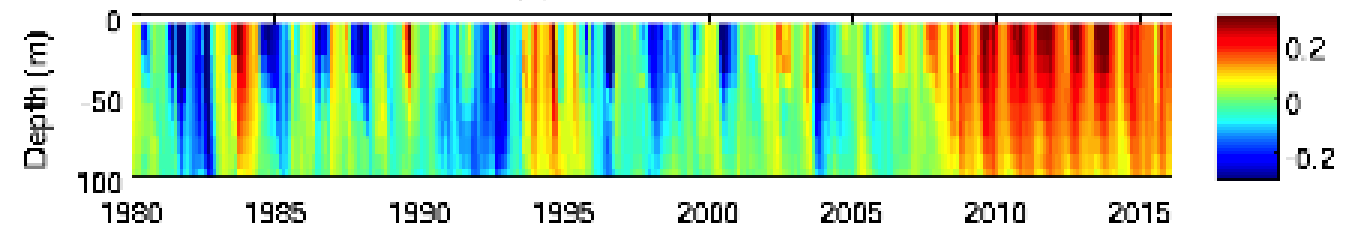

2 Figure S11: Monthly salinity anomalies at the four sections over 1980-2016, obtained by 3 subtracting climatological seasonal cycles from the time series in Fig. S10.

4 

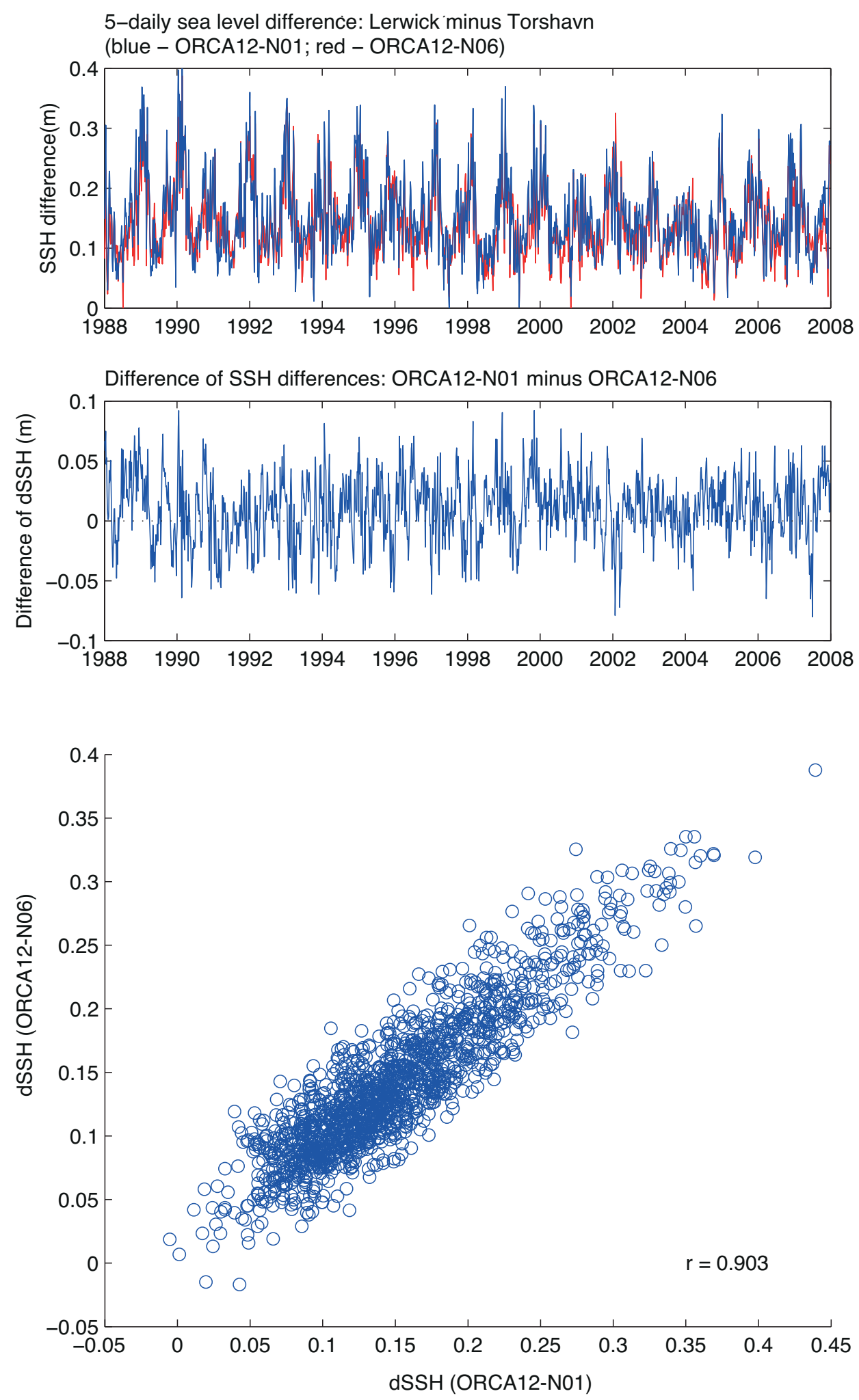

3 Figure S12. Comparison of ORCA12-N01 and ORCA12-N06 hindcasts over 1988-2007: 4 5-day averages of sea level difference, Lerwick minus Torshavn (top panel); ORCA125 N01 minus ORCA12-N06 differences (middle panel); scatterplot of individual sea level 6 differences. 